\title{
Econometric Analysis of Asymmetric Price Transmission Using Threshold Cointegration Approach: A Case Study of Morocco's Apple Markets
}

\author{
Ouahiba Elalaoui ${ }^{1, ~ *}$, Abdelouafi Ibrahimy ${ }^{1}$, Aziz Fadlaoui², Redouane Arrach ${ }^{3}$ \\ ${ }^{1}$ Department of Rural Economy, National School of Agriculture, Meknes, Morocco \\ ${ }^{2}$ Regional Agricultural Research Center in Meknes, National Institute of Agricultural Research, Meknes, Morocco \\ ${ }^{3}$ Strategy and Statistics Directorate, Ministry of Agriculture, Fisheries, Rural Development, Water and Forests, Rabat, Morocco \\ Email address: \\ ouahiba.elalaoui@gmail.com (O. Elalaoui) \\ ${ }^{*}$ Corresponding author
}

\section{To cite this article:}

Ouahiba Elalaoui, Abdelouafi Ibrahimy, Aziz Fadlaoui, Redouane Arrach. Econometric Analysis of Asymmetric Price Transmission Using Threshold Cointegration Approach: A Case Study of Morocco's Apple Markets. International Journal of Agricultural Economics. Vol. 3, No. 5, 2018, pp. 94-102. doi: 10.11648/j.ijae.20180305.11

Received: August 21, 2018; Accepted: September 14, 2018; Published: October 22, 2018

\begin{abstract}
The level of market integration between deficit and surplus markets is a key determinant of price stability and food security. Thus, market integration can be regarded as a way of assessing efficiency of agricultural markets. The current study intends to investigate the domestic market integration and explore the potential presence of asymmetric price adjustments between spatially separated markets. The paper employs threshold cointegration approach using monthly data of wholesale apples prices over the period from September 1993 to June 2017 in five major wholesale markets in Morocco. Study findings suggest that wholesale apples markets are significantly cointegrated, implying the presence of the long-run equilibrium relationships between the examined markets pairs. Considering the evidence as a whole, for five out of eight market pairings, the results reveal that the nature of price transmission exhibits significant asymmetric adjustments. Nonetheless, the empirical analysis does not always support the research hypothesis, stipulating that deficit market prices adjust more swiftly to price increases than to price decreases in surplus market because of the market power of intermediaries in the food marketing chain. Based on these results, the domestic market integration shows some signs of weakness, which may affect the progress of the sector. In this respect, further efforts should be made to enhance market performance so as to ensure an even balance between the production and marketing segment.
\end{abstract}

Keywords: Threshold Cointegration, Apples, Asymmetric Adjustments, Intermediaries

\section{Introduction}

Agricultural sector plays a major role in economic growth in Morocco by its contribution to the GDP of nearly $12 \%$ and provides employment for $40 \%$ of the population [1]. The sector continues also to contribute significantly to the country's food security through the supply of agricultural markets.

The significance of this sector has sparked renewed interest by the government, as shown by the implementation of a new development strategy dedicated specifically to agricultural sector, commonly known as "The Green
Morocco Plan", launched in 2008.

In this context, particular efforts have been devoted by both the government and professionals to promote the growth of agriculture. Thus, fruits and vegetables production recorded a substantial improvement with an average annual growth rate of $4.29 \%{ }^{1}$ over 2001-2015 period. However, the agricultural marketing still faces various challenges, such as a high level of taxation in wholesale markets and a presence of an informal sector with many intermediaries along marketing channels.

1 Calculated based on the statistical series of the Ministry of Agriculture, Fisheries, Rural Development, Water and forests. 
Despite the notable achievement accomplished in some segments, efficient marketing channels and well-integrated agricultural markets are essential for optimal distribution of production between deficit and surplus areas. With respect to several agricultural commodity chains, the apple sector has grabbed the attention of actors. Moreover, the apple tree represents $18 \%$ of the area of Rosaceae trees. The sector also ranks $2^{\text {nd }}$ among Rosaceae family after the almond tree and it is at the top of Rosaceae family with pips planted in Morocco. On the social front, the apple sector contributes to improving farmer's incomes totaling nearly 39000 producers [2].

Indeed, the apple sector has recorded significant growth in terms of area and production with average annual growth rates of $5.39 \%$ and $3.95 \%{ }^{2}$ over $2001-2016$ period, respectively. However, this substantial improvement, which is expected to increase the surplus of both production and consumption areas, is penalized by unsatisfactory marketing conditions, especially the predominance of intermediaries in the marketing channels that monopolize a large part of the added value of the sector. In addition to their impact through the distortion of price signals between surplus and deficit markets, the market power of commercial intermediaries can be a source of asymmetric price transmission in the sense that price increases may be transmitted more rapidly than price decreases $[3,4,5]$.

In fact, asymmetric price transmission issue is of a great interest in agricultural economics because its presence is regarded as a strong evidence of market failure and also a sign of welfare losses, suggesting that groups are not benefiting from a price reduction (buyers) or an increase (sellers) [6].

In view of advances in time series analysis, several studies have examined spatial market integration using cointegration framework, which has been extensively mobilized to analyze the long-run relationships among variables, using EngleGranger (1987) [7] and Johansen (1988) [8] approaches $[9,10,11,12]$. These techniques implicitly assume symmetric price adjustments in the sense that markets adjust similarly to both price increases and decreases, regardless of the nature of the shock. But, the literature points out that a whole range of factors may result in asymmetric adjustments towards longrun equilibrium, such as: market power of intermediaries, government interventions, transaction costs, stock behavior of traders and menu costs [3, 6]. Additionally, the empirical evidence reveals that asymmetric price transmission is a rule rather than an exception [13].

In this context, Enders and Siklos (2001) [14] suggest the threshold cointegration analysis, which extends the Engle and Granger's procedure (1987) to take into account the potential asymmetric adjustments towards the long-run equilibrium. Thus, the main assumption of this approach implies that transaction costs can prevent economic agents from continually adjusting. Economic agents only act to move the

2 Calculated based on the statistical series of the Ministry of Agriculture, Fisheries, Rural Development, Water and forests. system back to equilibrium when the deviation from the long-run equilibrium exceeds a critical threshold [15]. Accordingly, Enders and Siklos (2001) [14] highlight that the standard cointegration tests are misspecified and have low power if adjustment is asymmetric.

Internationally, the empirical literature on market integration analysis is widely developed, following the huge political interest of the subject as well as the development of econometric procedures. Within this framework, many studies have been carried out in order to assess the performance of agricultural markets [3, 4, 5, 16, 17, 18]. However, in Morocco, no empirical studies have been undertaken to investigate the spatial market integration issue. This work attempts to fill this gap by analyzing domestic market integration using threshold cointegration methodology, recently developed by Enders and Siklos (2001) [14].

The main purpose of this paper is to assess the market integration dynamics between five geographically dispersed markets. The specific objectives are twofold. First, the analysis attempts to test for cointegration between wholesale markets. Second, it explores the nature of price transmission in terms of symmetry and asymmetry. The investigation is based on two hypotheses: (i) the wholesale markets of apples are cointegrated because of the spatial market arbitrage of the economic actors and (ii) the price adjustment process is asymmetric due to the market power of intermediaries. The remainder of the paper is structured as follows: Section 2 focuses on data and outlines the econometric procedures. Subsequently, section 3 reports the empirical results and their implications. Finally, section 4 summarizes the main findings and section 5 concludes the paper by suggesting some recommendations.

\section{Data and Research Methodology}

\subsection{Data Collection and Study Scope}

The dataset for the analysis includes monthly price series from September 1993 to June 2017, measured in MAD per kilogram $(\mathrm{MAD} / \mathrm{Kg})$ and collected from Strategy and Statistics Directorate of Ministry of Agriculture, Fisheries, Rural Development, Water and forests in Morocco.

Five wholesale markets were selected, namely: Casablanca, Meknes, Agadir, Marrakech and Oujda. The criteria for selecting rely on the geographical dispersion, the representativeness of surplus and deficit areas as well as the availability of long time series of apples prices.

Meknes is an important apple production area in Morocco that supplies other deficit areas, especially during production periods. Likewise, Casablanca represents the main distribution platform that ensures the grouping of fruits and vegetables from different regions and their distribution throughout the country. Furthermore, this region is known to have storage units for many agricultural products, including apples. In contrast, the markets of Oujda, Agadir and Marrakech are mainly dominated by consumption, these 
deficit markets source primarily from production and distribution markets to meet their local demand.

The main purpose of this research is to gain a better understanding of the relationship between surplus markets (Casablanca and Meknes) and deficit markets (Oujda, Agadir and Marrakech), especially in terms of symmetry and asymmetry in prices adjustment. Hence, Casablanca and Meknes are considered as the reference markets. The others are analyzed with respect to these markets. Thus, all prices series were expressed in natural logarithm in order to dampen the amplitude of fluctuations as well as to interpret some estimated parameters in terms of elasticity.

\subsection{Econometric Analysis}

\subsubsection{Analysis of Statistical Properties of Variables}

As a first step, price transmission analysis requires examination of the univariate statistical properties of time series under study. At this stage, the data analysis is essential in determining both the appropriate modeling and the correct adjustment for seasonal price series.

(1) Seasonality analysis

Agricultural price series can exhibit pronounced seasonal variations, mainly as a result of the crop cycle. Indeed, it is known that prices are generally lower during production periods and higher during non-harvest periods. Additionally, failure to account for seasonality in agricultural price series can lead to inaccurate estimations. The seasonal component can be deterministic, stochastic or both [19]. The first is stable and repetitive, while the second is dynamic over time arising from some exogenous factors.

Determining the nature of seasonality is essential to accurately specify the appropriate method of seasonal adjustment [20]. In practical terms, a deterministic seasonality is modeled using seasonal dummy variables, whereas a stochastic seasonality is adjusted by means of filtering approach. Econometrically, specification of the nature of the seasonal component (deterministic or stochastic) relies on the seasonal unit root test, developed by Hegy (1990) [19] for quarterly data and extended by Franses (1990) [21, 22] and Beaulieu and Miron (1993) [23] for monthly data.

(2) Unit root analysis

The analysis of cointegration requires determining the order of series integration. A precondition for cointegration analysis implies that the considered variables are integrated of the same order. The empirical procedures start with unit root tests of each price series, in order to avoid spurious regression and misinterpretation of the results. Several unit root tests were performed to verify the results robustness (Augmented Dickey Fuller (ADF), KPSS and Perron 1997 [24] tests).

\subsubsection{Modeling Asymmetric Price Transmission}

The methodological approach for the threshold cointegration analysis can be summarized in the following steps:

Step 1: Estimation of a long-run relationship between deficit markets and surplus markets pairings:

$$
\mathrm{P}_{\mathrm{t}}^{\mathrm{d}}=\alpha+\beta \mathrm{P}_{\mathrm{t}}^{\mathrm{s}}+\varepsilon_{\mathrm{t}}
$$

Where $\mathrm{P}_{\mathrm{t}}^{\mathrm{d}}$ and $\mathrm{P}_{\mathrm{t}}^{\mathrm{s}}$ are the natural logarithm of apples prices in deficit market and surplus market at time t, respectively; $\alpha$ is constant term; $\beta$ is the long-run transmission elasticity; and $\varepsilon_{\mathrm{t}}$ is disturbance term which may be serially correlated. It measures the deviation from the equilibrium between $P_{t}^{S}$ and $\mathrm{P}_{\mathrm{t}}^{\mathrm{d}}$.

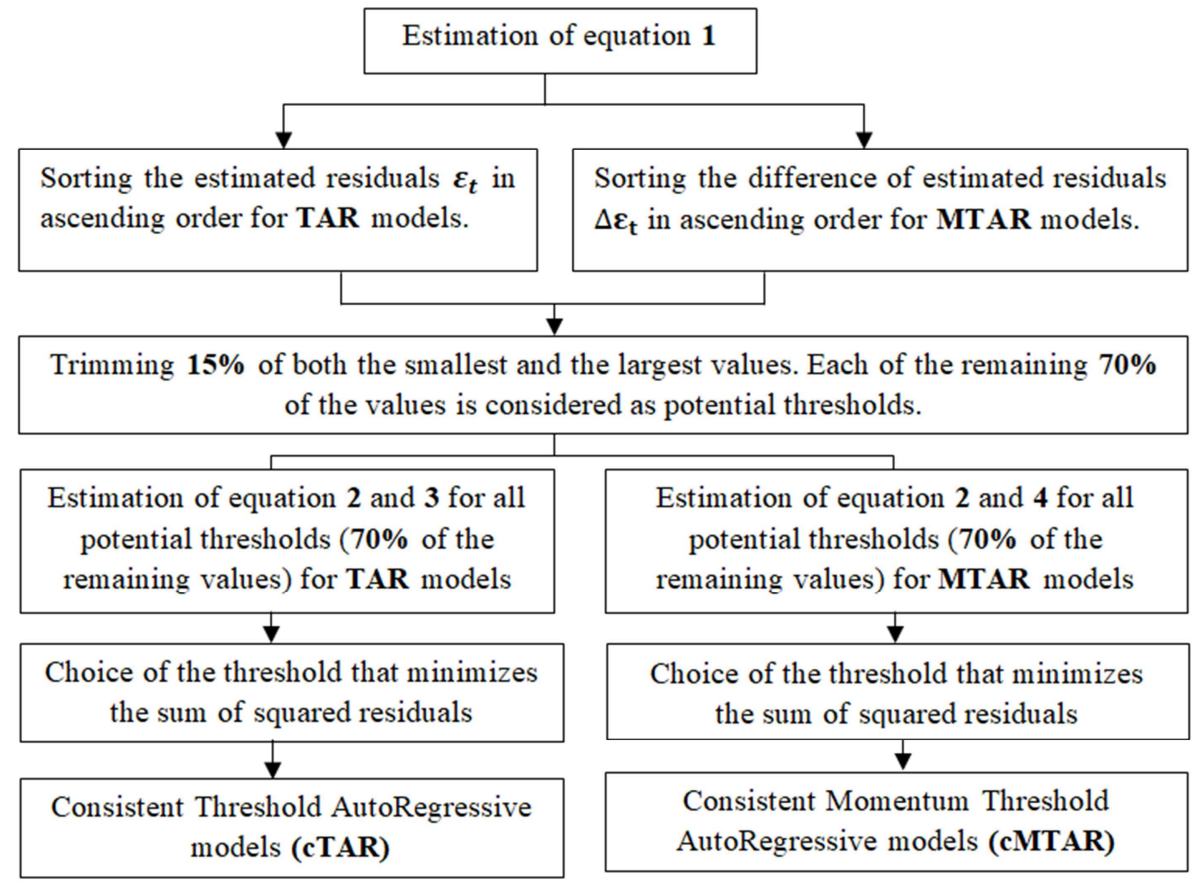

Source: Author's own elaboration

Figure 1. Chan's methodology for determining threshold values $\tau$. 
Step 2: Estimation of threshold cointegration models:

To allow for asymmetric adjustment dynamics, Enders and Siklos (2001) [14] extend the Engle and Granger's procedure (1987) [7] by proposing the following specification:

$$
\Delta \varepsilon_{t}=I_{t} \rho_{1} \varepsilon_{t-1}+\left(1-I_{t}\right) \rho_{2} \varepsilon_{t-1}+\sum_{i=1}^{\rho} \gamma_{i} \Delta \varepsilon_{t-i}+\mu_{t}
$$

Where $\Delta$ is the difference operator, $\varepsilon_{t}$ is the residuals obtained from equation (1), $\rho_{1}$ and $\rho_{2}$ refer to adjustment coefficients for positive and negative deviations. The optimal lag length $\rho$ of the dependent variable $\Delta \varepsilon_{t}$ is determined based on information criterions in order to make the error term $\mu_{t}$ a white noise process.

$\tau$ is the value of the threshold, which is determined by Chan's (1993) [25] methodology, as shown in figure 1. The consistent threshold value is selected by minimizing the Sum of Squared Residuals of equation (2).

$I_{t}$ is the Heaviside indicator function, defined as follows:

In the case of Threshold AutoRegressive model (TAR)

$$
I_{t}=\left\{\begin{array}{l}
1 \text { if } \varepsilon_{t-1} \geq \tau \\
0 \text { if } \varepsilon_{t-1}<\tau
\end{array}\right.
$$

In TAR model, the Heaviside indicator depends on the level of $\varepsilon_{t-1}$. In fact, if $\varepsilon_{t-1}$ is bigger than the threshold $\tau$, the adjustment towards the long-run equilibrium is $\rho_{1}$. Otherwise, if $\varepsilon_{t-1}$ is smaller than the threshold $\tau$, the adjustment is $\rho_{2}$.

In the case of Momentum Threshold AutoRegressive model (MTAR)

$$
I_{t}=\left\{\begin{array}{l}
1 \text { if } \Delta \varepsilon_{t-1} \geq \tau \\
0 \text { if } \Delta \varepsilon_{t-1}<\tau
\end{array}\right.
$$

In MTAR model, the Heaviside indicator depends on the previous period's change in $\varepsilon_{t-1}$. The latter model is proposed by Enders and Granger (1998) [26] and Enders and Siklos (2001) [14] to take into account steep variations in the residuals. Indeed, MTAR model is particularly useful when the $\varepsilon_{t}$ series exhibits more momentum in one direction than the other.

Step 3: Optimal model selection:

Subsequently, in order to determine the powerful model,

$$
\Delta P_{t}^{d}=\alpha_{0}+\sum_{k=1} \alpha_{K} \Delta P_{t-k}^{d}+\sum_{k=0} \beta_{K} \Delta P_{t-k}^{S}+\rho_{1.1} I_{t} \varepsilon_{t-1}+\rho_{2.1}\left(1-I_{t}\right) \varepsilon_{t-1}+\omega_{t}
$$

Where $\Delta P_{t}^{d}$ and $\Delta P_{t}^{s}$ are the wholesale first differences prices in deficit and surplus market at time $t$, respectively; $\rho_{1.1}$ and $\rho_{2.1}$ indicate the speed of adjustment to positive and negative deviations from long-run equilibrium, respectively; $\alpha_{K}$ and $\beta_{K}$ refer to short-run adjustment coefficients; $I_{t}$ is the Heaviside indicator function and $\omega_{t}$ is the error term.

In contrast, when the price adjustment is symmetric, a symmetric standard error correction model can be estimated as follows:

$$
\Delta P_{t}^{d}=\alpha_{0}+\sum \alpha_{K} \Delta P_{t-k}^{d}+\sum \beta_{k} \Delta P_{t-k}^{s}+p \varepsilon_{t-1}+\omega_{t}(6)
$$

Where $\Delta P_{t}^{d}, \Delta P_{t}^{s}, \alpha_{K}, \beta_{k}$, and $\omega_{t}$ are as defined in Equation (5); $p$ is the speed of adjustment and $\varepsilon_{t-1}$ is the the threshold value is firstly set equal to zero $(\tau=0)$ for both TAR and MTAR models and secondly specified by chan's (1993) [25] methodology ( $\tau$ is unknown). Accordingly, for each pair of markets under examination, four threshold cointegration models are considered. First, TAR and MTAR models were estimated, with threshold value equal to zero. Then, cTAR and cMTAR models were estimated, both with consistent threshold value estimated using Chan's procedure.

The optimum model is selected using the Akaike's Information Criterion (AIC), Bayesian Information Criterion (BIC) and Hannan-Quinn Information Criterion (HQIC). A model with the lowest AIC, BIC and HQIC will be used for cointegration and asymmetry tests.

Step 4: Testing for cointegration:

The cointegration test performed on threshold cointegration models is based on the $\rho_{1}$ and $\rho_{2}$ coefficients. Enders and Siklos (2001) [14] suggest two statistic tests: t-max (The largest of the individual t-statistics of $\rho_{1}$ and $\rho_{2}$ is called t-max) and $\Phi$ which corresponds to non-standard F-statistic of the joint null hypothesis of no cointegration $\rho_{1}=\rho_{2}=0$. The rejection of the null hypothesis implies the existence of a longrun equilibrium relationship between price series.

Step 5: Testing for asymmetry:

After confirming the existence of cointegration between price series, the null hypothesis of symmetric adjustment $\left(\rho_{1}=\rho_{2}\right)$ can be tested against the alternative $\left(\rho_{1} \neq \rho_{2}\right)$ using the standard F-test. Thus, rejection of the null hypothesis implies the presence of asymmetry in price adjustments.

Step 6: Estimation of error correction models:

In the final analytic step, following the Granger representation theorem, when the variables are cointegrated, an error correction model can be estimated to examine the short-run dynamics [7]. In the presence of asymmetry, the variables can be modeled as an asymmetric error correction model in which the speed of adjustment depends on the nature of the deviations (positive or negative). In this research, the asymmetric error correction model with threshold adjustment is specified as follows:

\section{Results and Discussion}

\subsection{Descriptive Statistics}

Table 1 presents summary statistics for seasonally unadjusted prices across the five wholesale markets under study. The spatial comparison of prices reveals that the minimum values of the average price are observed in both Casablanca and Meknes markets with 5.93 MAD/KG while the maximum average wholesale price is $8.60 \mathrm{MAD} / \mathrm{KG}$ observed in Agadir Market. Furthermore, by comparing variation coefficients of the five markets, Casablanca shows 
more price volatility (40\%), while Agadir records less price variability $(23 \%)$. Figure 2 reveals that prices displays similar seasonal pattern for the five markets. In general, apples prices start to increase above the annual average price from January to May and reach their maximum level in May. In contrast, prices come down below the annual average price between July and November with the lowest values in July and October.

Table 1. Descriptive Statistics of wholesale apples prices.

\begin{tabular}{lllll}
\hline Market & Casablanca & Meknes & Oujda & Marrakech \\
\hline Mean & 5.92 & 5.94 & 6.33 & 7.50 \\
Max & 12.26 & 14.47 & 13.73 & 14.41 \\
Min & 2.08 & 2.94 & 2.01 & 2.51 \\
Std. Dev. & 2.37 & 1.58 & 2.38 & 2.52 \\
Coeff. Var. (\%) & 40 & 26 & 37 & 2.00 \\
\hline
\end{tabular}

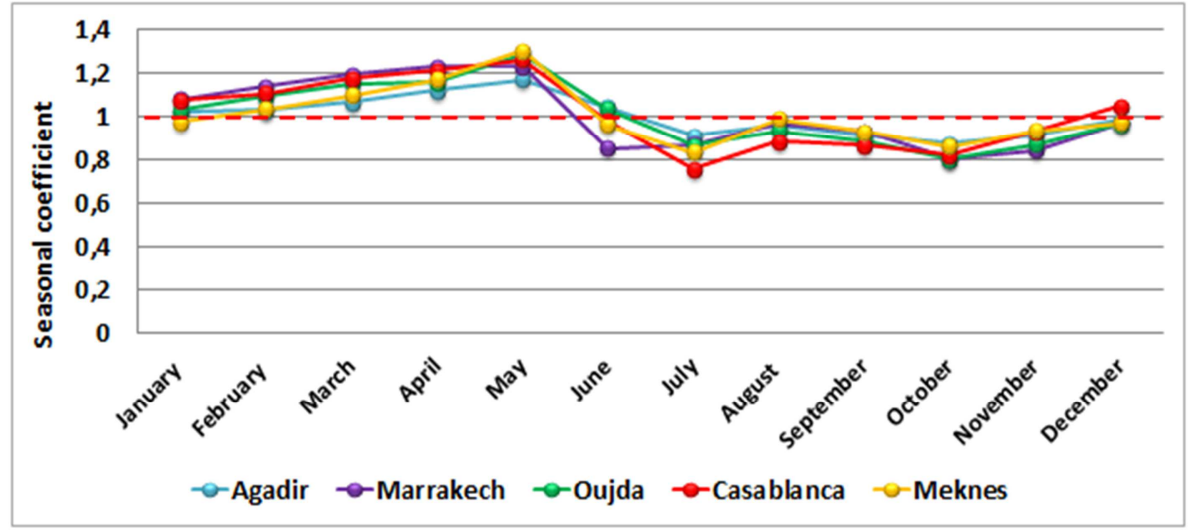

Figure 2. Seasonal coefficients of price series.

\subsection{Statistical Properties of price Series}

Table 2 reports the econometric results of Hegy test, which permits the examination of both seasonal and non-seasonal unit root.

Table 2. Results of HEGY Test for Seasonal Unit Root.

\begin{tabular}{llllll}
\hline Null hypothesis & Casablanca & Meknes & Oujda & Marrakech & Agadir \\
\hline$\pi_{1}=0$ & -2.09 & -2.92 & -1.57 & -1.69 & -2.09 \\
$\pi_{2}=0$ & $-4.29 * * *$ & $-3.19 * *$ & $-4.08 * * *$ & -2.55 & $-4.60 * * *$ \\
$\pi_{3}=\pi_{4}$ & $22.06 * * *$ & $9.50 * * *$ & $14.02 * * *$ & $9.77 * * *$ & $24.34 * * *$ \\
$\pi_{5}=\pi_{6}$ & $24.73 * * *$ & $15.69 * * *$ & $11.79 * * *$ & $12.60 * * *$ & $\pi$ \\
$\pi_{7}=\pi_{8}$ & $15.89 * * *$ & $9.91 * * *$ & $7.05 * *$ & $6.19 * *$ & $\frac{\pi}{2}$ \\
$\pi_{9}=\pi_{10}$ & $24.96 * * *$ & $12.94 * * *$ & $15.83 * * *$ & $9.34 * * *$ & $16.50 * * *$ \\
$\pi_{11}=\pi_{12}$ & $25.41 * * *$ & $9.00^{* * *}$ & $14.50 * * *$ & $\frac{2 \pi}{3}$ & $26.09 * * *$ \\
\hline
\end{tabular}

Notes:

The test includes seasonal dummies, constant, and a trend;

The optimal lag needed to remove serial correlation is automatically selected by relying on information criterions;

$* * *, * *$ and $*$ denote rejection of the null hypothesis at the $1 \%, 5 \%$ and $10 \%$ level of significance, respectively.

The results accept the existence of a unit root at the zero frequency for all price series at the conventional levels of significance. The main implication of this finding suggests that the prices series may exhibit a stochastic trend. Thus, for the rest of the frequencies, the results reveal that the null hypothesis generally is rejected, implying the absence of the seasonal unit root in data. Consequently, the price series exhibit a deterministic seasonal component. In this case, seasonal adjustment implies the regression of series on seasonal dummies variables. As a consequence, the residuals were used as the seasonally adjusted variables for a thorough analysis.
In order to meet the required conditions for cointegration, a set of unit root tests was undertaken, particularly the Augmented Dickey Fuller (ADF) test, KPSS test and Perron (1997) test. The results ${ }^{3}$ indicate that all price series are non-stationary at level and stationary at first difference. Thus, the variables are I (1) at conventional significance level (5\%).

\subsection{Threshold Cointegration Estimations}

Table 3 and table 4 summarize the results of threshold

3 The ADF, KPSS and Perron (1997) test results are not presented but are available from authors upon request. 
cointegration. All models were estimated and the one with the best performance was selected and presented here for further analysis. Generally, the results indicated that the cMTAR model provides better estimates than the TAR model. The null hypothesis of no cointegration, that is, $\rho_{1}=\rho_{2}=0$, is rejected in favor of its presence for all pairs of markets at the conventional significance levels, suggesting a long-run equilibrium relationship between the pairs of wholesale markets under examination. Accordingly, the practical implication of this result is that the prices in the major wholesale markets are connected and linked, although they are significantly dispersed. Interestingly, the price signals are transferred from surplus markets to deficit markets. Consequently, given that the pairs of wholesale markets are cointegrated, the null hypothesis of symmetric adjustment $\left(\rho_{1}=\rho_{2}\right)$ can be tested. The F-statistics failed to reject the null hypothesis at all levels of significance for Oujda-Meknes, Marrakech-Meknes and Casablanca-Meknes pairs markets, indicating that Oujda, Marrakech and Casablanca markets display symmetric adjustment in response to changes in Meknes's market price.

On the contrary, The F-statistics revealed an asymmetric price adjustment when the prices adjust to restore the longrun equilibrium in five market pairs, namely: AgadirMeknes, Agadir-Casablanca, Oujda-Casablanca, MarrakechCasablanca and Meknes-Casablanca. Indeed, the point estimate of $\rho_{1}$ and $\rho_{2}$ for Oujda-Casablanca and MeknesCasablanca market pairs suggests that respectively $48 \%$ and $51 \%$ of negative deviations from the equilibrium are monthly corrected, whereas only $20 \%$ and $33 \%$ of positive deviations are removed over the same period.

In the other case, Agadir and Marrakech markets adjust faster to positive discrepancies from the equilibrium in comparison with the negative ones in response to shocks in Casablanca's market price. Likewise, Agadir market display asymmetric adjustments with respect to Meknes market in the sense that positive deviations are eliminated faster than negative deviations. In fact, the point estimate of $\rho_{1}$ and $\rho_{2}$ for Agadir-Meknes, Agadir-Casablanca and MarrakechCasablanca indicates that positive discrepancies from the equilibrium are corrected faster respectively at a rate of $30 \%$, $31 \%$ and $44 \%$ within a month. Conversely, just $11 \%, 12 \%$ and $26 \%$ of negative discrepancies are eliminated of each month, respectively for the same pairings considered.

Overall, in view of this analysis, the results reveal the presence of three types of price adjustments between surplus markets and deficit markets, namely: symmetric price transmission (3 cases), positive asymmetry ( 2 cases) and negative asymmetry ( 3 cases).

Furthermore, it should be noted that all wholesale markets adjust symmetrically to changes in Meknes market, except Agadir Market. In contrast, the price adjustments of market pairs with respect to Casablanca market are significantly asymmetric. Additionally, the empirical analysis revealed that there are various cases in which markets adjust more quickly to price decreases than to increases. However, this type of asymmetric adjustment is often observed for perishable products because of traders' behavior. The latter are sometimes forced to favor price decreases and limit price increases, in order to minimize the risk of losing the product.

This unexpected result in the case of apples, regarded as a product suitable for storage for a long time, could be attributable to insufficient storage units for apples. In fact, during the season of high production, the intermediaries could rely on price declines than increases, in order to sell quickly the products due to storage unit's lack.

Table 3. Results of threshold cointegration analysis (Meknes as the reference market).

\begin{tabular}{|c|c|c|c|c|}
\hline Market pairs & Agadir-Meknes & Oujda-Meknes & Marrakech-Meknes & Casablanca-Meknes \\
\hline Optimal model & Consistent MTAR & Consistent MTAR & Consistent MTAR & Consistent MTAR \\
\hline Lag & 1 & 1 & 1 & 1 \\
\hline$\rho_{1}$ & -0.30 & -0.30 & -0.28 & -0.28 \\
\hline$\rho_{2}$ & -0.11 & -0.40 & -0.44 & -0.18 \\
\hline$\tau$ & 0.10 & -0.21 & -0.24 & 0.01 \\
\hline$\Phi-$ Statistic $\left(\rho_{1}=\rho_{2}=0\right)$ & $12.54 * * *$ & $21.57 * * *$ & $23.91 * * *$ & $14.60 * * *$ \\
\hline F - Statistic $\left(\rho_{1}=\rho_{2}\right)$ & $5.08 * *$ & 0.95 & 2.36 & 1.46 \\
\hline
\end{tabular}

Notes :

$* * *, * *$ and $*$ denote rejection of the null hypothesis at the $1 \%, 5 \%$ and $10 \%$ level of significance, respectively;

The optimal lag needed to remove serial correlation is automatically selected by relying on information criterions.

Table 4. Results of threshold cointegration analysis (Casablanca as the reference market).

\begin{tabular}{|c|c|c|c|c|}
\hline Market pairs & Agadir-Casablanca & Oujda-Casablanca & Marrakech-Casablanca & Meknes-Casablanca \\
\hline Optimal model & Consistent MTAR & Consistent TAR & Consistent MTAR & MTAR with null threshold \\
\hline Lag & 1 & 1 & 1 & 4 \\
\hline$\rho_{1}$ & -0.31 & -0.20 & -0.44 & -0.33 \\
\hline$\rho_{2}$ & -0.12 & -0.48 & -0.26 & -0.51 \\
\hline$\tau$ & 0.10 & -0.23 & 0.02 & 0 \\
\hline$\Phi-$ Statistic $\left(\rho_{1}=\rho_{2}=0\right)$ & $13.64 * * *$ & $24.61 * * *$ & $27.13 * * *$ & $20.53 * * *$ \\
\hline$F-$ Statistic $\left(\rho_{1}=\rho_{2}\right)$ & $5.43 * *$ & $9.66 * * *$ & $3.89 * *$ & $3.39 *$ \\
\hline
\end{tabular}

Notes :

$* * *, * *$ and $*$ denote rejection of the null hypothesis at the $1 \%, 5 \%$ and $10 \%$ level of significance, respectively;

The optimal lag needed to remove serial correlation is automatically selected by relying on information criterions. 
Finally, in order to have a better understanding of the dynamic adjustments to both positive shocks (a decrease in the surplus market price) and negative shocks (an increase in the surplus market price), impulse response functions have been estimated from the asymmetric error correction models for providing further evidence about the dynamic interrelationships between prices at surplus and deficit markets. In the case of Oujda-Casablanca market pair, figure 3 indicates that the margin returns to its equilibrium within 7 months in response to negative shock. However, it takes approximatively about 21 months to return to equilibrium with regard to positive shock in marketing margin.
Similarly, in the case of Meknes-Casablanca pairing, as shown in Figure 4, negative shocks revert faster to the equilibrium level than positive shocks. In such a case, the time needed to restore equilibrium takes 8 months and 15 months to adjust to negative and to positive shocks, respectively.

In sum, the findings reveal that positive shocks to the marketing margin tend to persist for a long time regarding the pairs highlighted above, but relatively the negative shocks revert quickly towards equilibrium. These results are consistent with Ankamah-Yeboah (2012) [4], implying that the markets respond more quickly to shocks that squeeze the marketing margins than shocks that stretch the marketing margins.

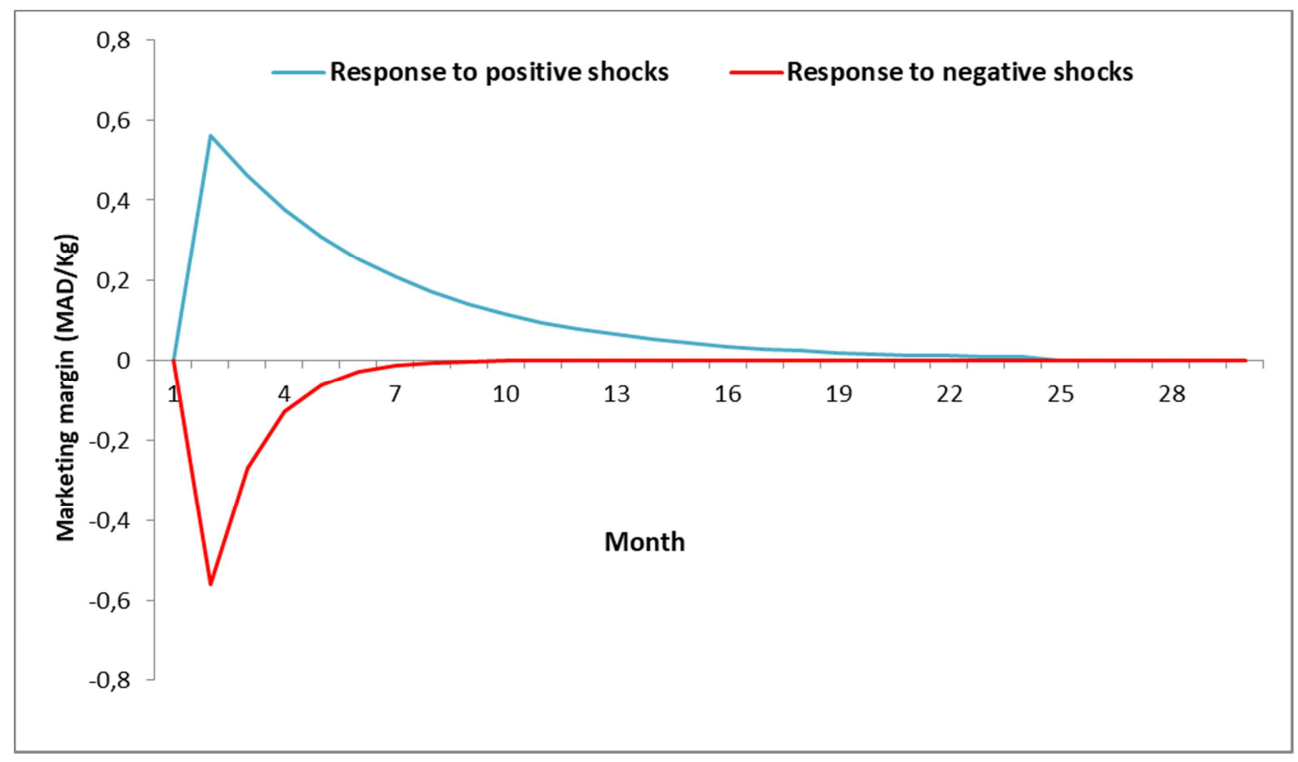

Figure 3. Asymmetric response of wholesale prices in Oujda to prices in Casablanca.

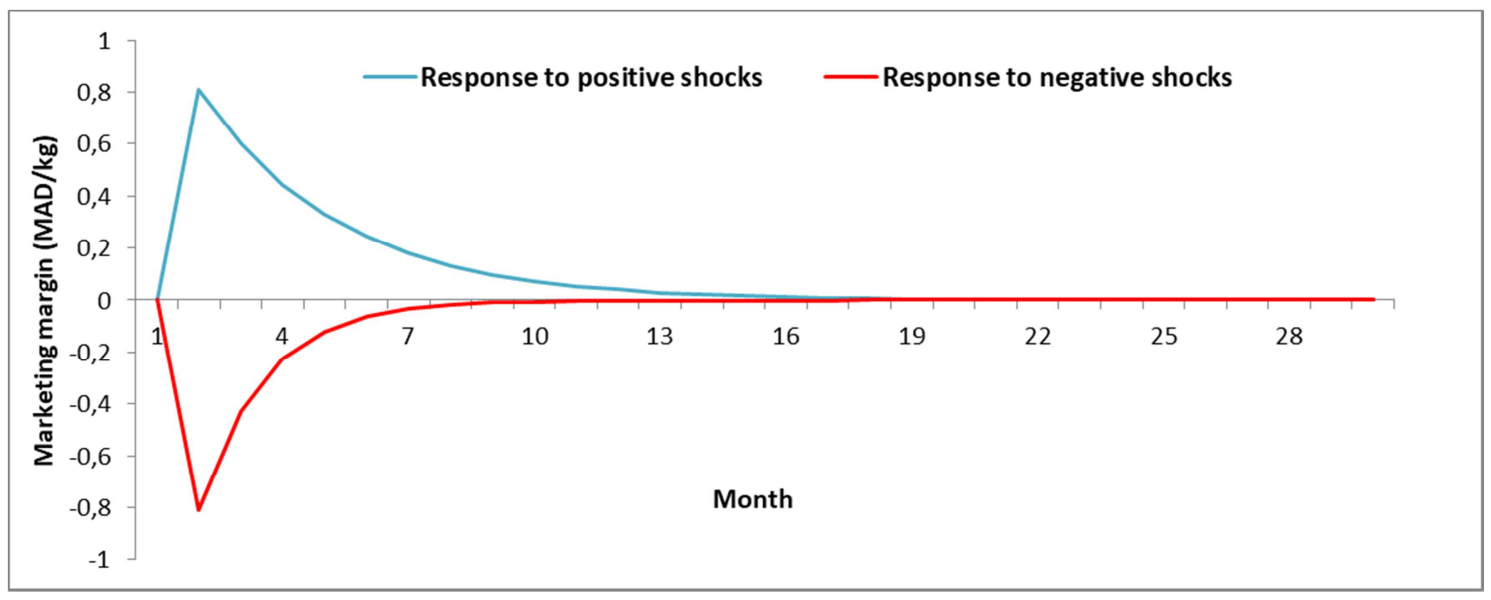

Figure 4. Asymmetric response of wholesale prices in Meknes to prices in Casablanca.

In contrast, in the case of Marrakech-Casablanca market pair, presented in figure 5, the results show that the margin achieve the equilibrium level over a period of 11 months in reaction to positive shock, whereas it takes about 16 months to join the equilibrium with respect to negative shock. In such a case, there is faster convergence for the positive shocks versus the negative ones. Additionally, the markets react quickly to price movements that stretch the marketing margins than movements that squeeze them.

Similarly, in the case of Agadir-Meknes and AgadirCasablanca, depicted in figure 6 and 7, the results show that the adjustment time oscillate between 12 and 14 months to adjust to positive shocks and approximatively between 30 and 32 months to adjust to negative shocks. In that case, the 
negative shocks are persistent and required a long time to establish the equilibrium, whereas there is faster convergence for the positive shocks. Therefore, the markets react quickly to price movements that stretch the margin than movements that squeeze them.

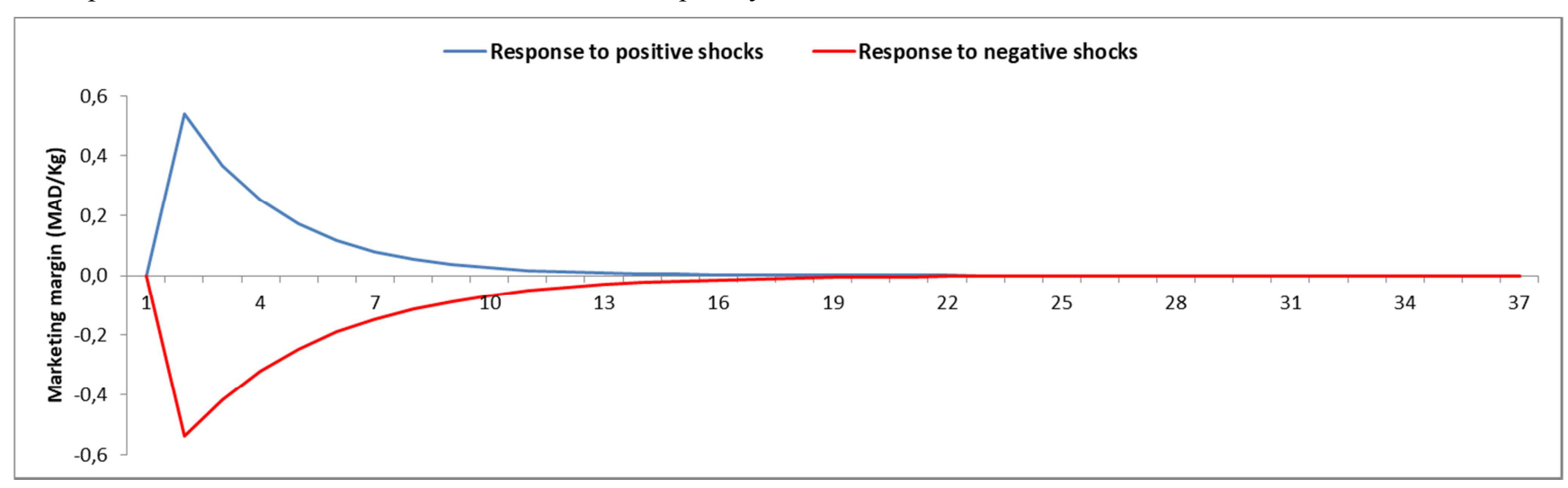

Figure 5. Asymmetric response of wholesale prices in Marrakech to prices in Casablanca.

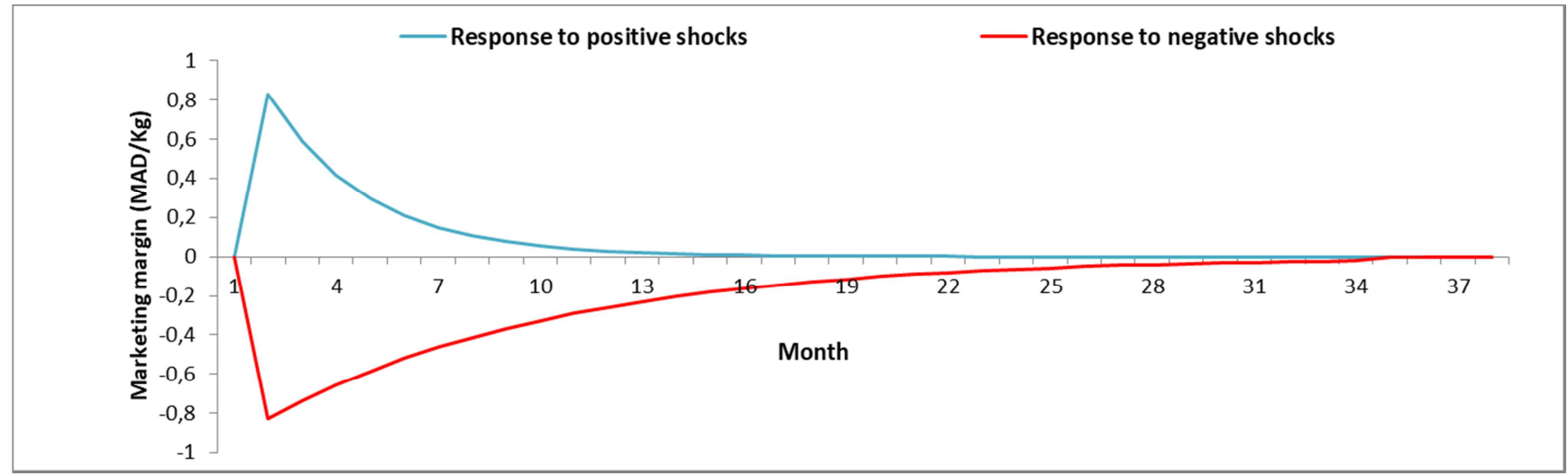

Figure 6. Asymmetric response of wholesale prices in Agadir to prices in Meknes.

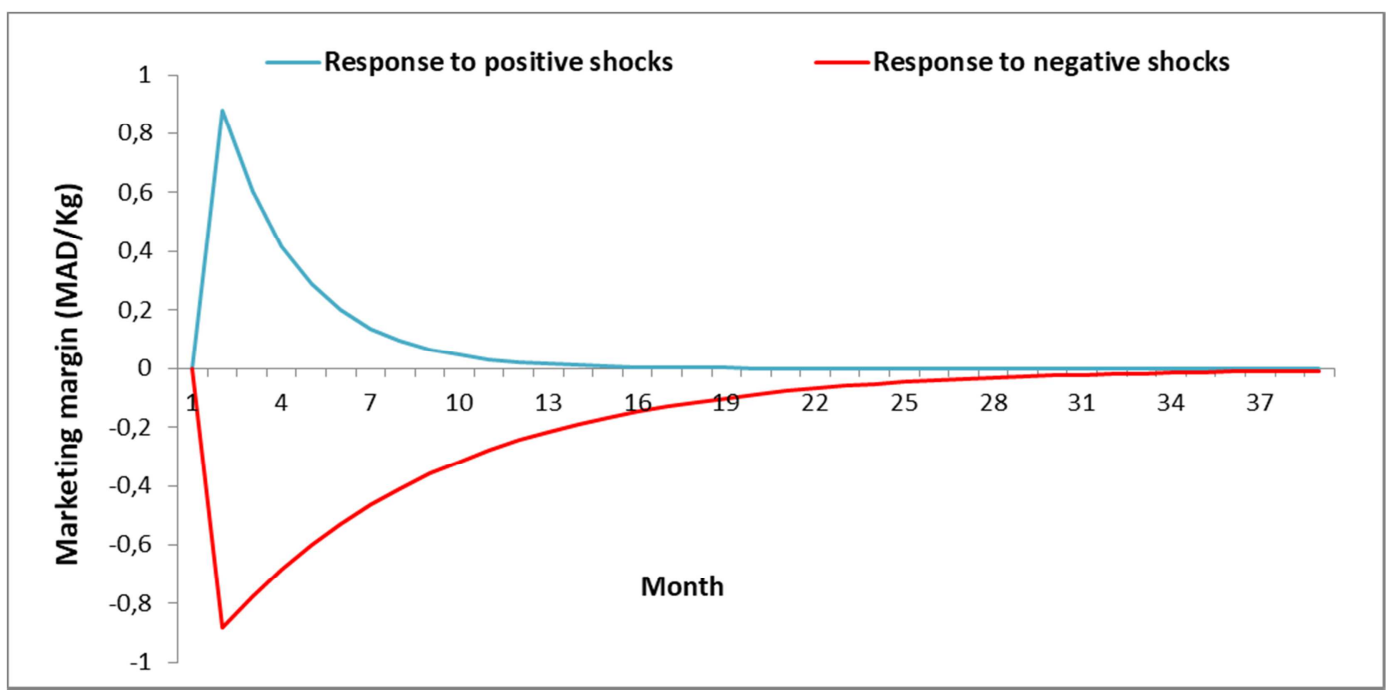

Figure 7. Asymmetric response of wholesale prices in Agadir to prices in Casablanca.

\section{Conclusion}

This paper investigated the domestic market integration and the nature of price transmission, using time series techniques, especially the threshold cointegration approach for five major wholesale markets in Morocco. The main finding revealed that the wholesale markets are cointegrated for the case of apple sector, suggesting that prices in surplus and in deficit markets move together in the long-run over time.

Overall, the results confirm the presence of both positive and negative asymmetry, and thus evidence of market failure. Additionally, the nature of asymmetric adjustments does not 
always support the assumption that the wholesale prices in the deficit markets react more rapidly to price increases than to price decreases originating at the surplus markets, because of the market power of intermediaries.

Furthermore, there is evidence of deficit markets responding much faster to price decreases than to price increases in surplus markets for three out of eight market pairs, often observed in the case of perishable products. This unexpected conclusion implicitly refers to the lack of storage units' capacity for apple sector.

\section{Recommendations}

On the basis of the study, several recommendations can be drawn up in order to enhance the performance of domestic agricultural markets. For this purpose, it is highly recommended to boost the development of storage units in order to promote symmetric price adjustments as well as to reduce the pronounced seasonality of apple prices. Also, both government and professionals should improve the marketing conditions for agricultural products in the wholesale markets in addition to strengthen short distribution channels. The latter can be further enhanced by aggregating smallholder farmers in order to pool required resources, to minimize significantly marketing costs, and finally, to reduce the number of intermediaries in the distribution channels.

\section{References}

[1] Ministère de l'Agriculture, de la Pêche Maritime, du Développement Rural et des Eaux et Forêts, 2016. «L'AGRICULTURE EN CHIFFRES 2016»

[2] Ministère de l'Agriculture, de la Pêche Maritime, du Développement Rural et des Eaux et Forêts, 2014. « Note de veille : pomme »

[3] Abdulai, A. 2000. "Spatial price transmission and asymmetry in the Ghanaian maize market" Journal of Development Economics. Vol. 63 (2), 327-349.

[4] Ankamah-Yeboah, I. 2012. "Spatial Price Transmission in the Regional Maize Markets in Ghana." Munich Personal RePEc Archive, MPRA Paper No. 49720.

[5] Larvoe, N. 2015. "Integration Assessment of Regional Yam Markets in Ghana: A Spatial Price Analysis". Master's thesis, Swedish University of Agricultural sciences.

[6] Meyer, J. and von Cramon-Taubadel, S. (2004). "Asymmetric Price Transmission: A Survey". Journal of Agricultural Economics, vol. 55(3), 581-611.

[7] Engle, R. F., Granger, C. W. J., 1987. "Co-integration and error correction: representation, estimation, and testing". Econometrica, Vol. 55 (2), 251-276.

[8] Johansen, S. (1988). "Statistical Analysis of Cointegration Vectors". Journal of Economic Dynamics and Control, Vol. $12,231-254$.

[9] Habte, Z. 2017 "Spatial market integration and price transmission for papaya markets in Ethiopia". Journal of
Development and Agricultural Economics, Vol. 9(5), 129-136.

[10] Ahmad Beag, F. Singla. N. 2014 “Cointegration, Causality and Impulse Response Analysis in Major Apple Markets of India”. Agricultural Economics Research Review, Vol. 27 (No.2), 289-298.

[11] Ghafoor, A. Mustafa, K. Mushtaq, K. Abedullah. 2009. "Cointegration and Causality: An Application to Major Mango Markets in Pakistan" The Lahore Journal of Economics, 14 (1), pp. 85-113.

[12] Paul, U. K. Das, G. Debnath, A. Mathur, T. 2017. "Market Integration and Price Leadership in India's Onion Market". Review of Market Integration, 8(1\&2) 49-64.

[13] Peltzman, S. (2000). Prices Rise Faster than they fall, Journal of Political Economy, Vol. 108(3), 466-502.

[14] Enders, W. Siklos, P. 2001. "Cointegration and threshold adjustment". Journal of Business and Economic Statistics. Vol. 19, 166-176.

[15] Abdulai, A. 2002. "Using Threshold Cointegration to estimate asymmetric Price Transmission in the Swiss Pork Market". Applied Economics. Vol. 34, 679-687.

[16] Kofi Blay, J. 2015. "Spatial Market Integration and Price Transmission of Important Crop Markets in Ghana". Master of Science in Agriculture (Agricultural Economics).

[17] Hassanzoy, N. Ito, S. Isoda, H. Amekawa, Y. 2016. "Cointegration and spatial price transmission among wheat and wheat-flour markets in Afghanistan". Applied Economics.

[18] Ilyasov, J. Götz, L. Akramov, K. T. Dorosh, P. Glauben, T. 2016. "Market Integration and Price Transmission in Tajikistan's Wheat Markets: Rising Like Rockets but Falling Like Feathers?”. International Food Policy Research Institue.

[19] Hylleberg, S., Engle, R. F., Granger, C. W. J. and Yoo, B. S. (1990). "Seasonal Integration and Cointegration", Journal of Econometrics. Vol 44, 215-238.

[20] Mendez Parra, M. 2015. "Seasonal Unit Roots and Structural Breaks in agricultural time series: Monthly exports and domestic supply in Argentina". University of Sussex, Munich Personal RePEc Archive.

[21] Franses, P. H. (1990). "Testing for seasonal unit roots in monthly data". Erasmus University, Rotterdam.

[22] Franses, P. H. 1991. "Seasonality, Non-Stationarity and the Forecasting of Monthly Time Series. International Journal of Forecasting". Vol. 7, $199-208$

[23] Beaulieu, J. J. and Miron, J. A. (1993). "Seasonal unit roots and déterministic seasonal in aggregate U.S. Data", Journal of Econometrics. Vol. 55, 305-328.

[24] Perron, P. 1997. "Further evidence on breaking trend functions in macroeconomic variables". Journal of Econometrics. Vol $80,355-385$.

[25] Chan, K. S. 1993. "Consistency and limiting distribution of the least squares estimator of the threshold autoregressive model”. The Annals of Statistics. Vol. 21, 520-533.

[26] Enders, W., and Granger, C. W. J. 1998. "Unit-root tests and asymmetric adjustment with an example using the term structure of interest rates". Journal of Business \& Economic Statistics. Vol. 16, 304-311. 